\title{
DOI: 10.33947/1981-741X-v20n2-4877 \\ DESAFIOS DA GESTÃO DE RESÍDUOS SÓLIDOS ORGÂNICOS URBANOS E A SUA CONTRIBUIÇÃO PARA ARBORIZAÇÃO URBANA
}

\section{CHALLENGES OF URBAN ORGANIC SOLID WASTE MANAGEMENT AND ITS CONTRIBUTION TO URBAN AFFORESTATION}

\author{
Joelma Telesi Pacheco Conceição¹, Marcio Magera Conceição², Ricardo Costa ${ }^{3}$, Fabricio Bau Dalmas4, Mauricio \\ Lamano Ferreira ${ }^{5}$
}

\author{
Submetido em: 03/12/2021 \\ Aprovado em: 03/12/2021
}

\begin{abstract}
RESUMO
A gestão de Resíduos Orgânicos faz parte do desafio imposto pelas alterações climáticas por liberarem metano e gás carbônico na atmosfera como resultado de seu processo de decomposição, contribuindo com $4 \%$ da poluição por Gases de Efeito Estufa. Este estudo tem por objetivo analisar experiências de reaproveitamento de resíduos orgânicos desenvolvidas no Brasil e relatadas em artigos científicos publicados no período de 2010 a 2021, com especial ênfase para o reaproveitamento de produtos da decomposição (i.e. chorume) na adubação de árvores urbanas. Trata-se de uma pesquisa qualitativa para qual foram consultadas as plataformas Scientific Electronic Library Online (SCIELO) e Google Acadêmico, buscando artigos nacionais, através dos descritores: Iniciativas reaproveitamento de resíduos orgânicos, Resíduos orgânicos urbanos, Resíduos orgânicos experiência de compostagem, Compostagem de resíduos orgânicos e Reaproveitamento de Resíduos Orgânicos. Foram encontrados 36 artigos dos quais, após análise do conteúdo, foram selecionados 6 estudos cujo conteúdo atendeu aos interesses da pesquisa. Concluiu-se que as ações que vêm se desenvolvendo para o reaproveitamento de Resíduos Orgânicos partem de pequenas iniciativas, regionalizadas, com resultados positivos e desenvolvidas por uma parcela da população que optou por agir de maneira sustentável diante do descaso das entidades públicas frente aos problemas sanitários e ambientais relacionados à gestão de resíduos Orgânicos.
\end{abstract}

PALAVRAS-CHAVE: Resíduos Orgânicos. Reaproveitamento de Resíduos orgânicos. Gestão de Resíduos

\begin{abstract}
Organic Waste management is part of the challenge imposed by climate change by releasing methane and carbon dioxide into the atmosphere as a result of its decomposition process, contributing $4 \%$ of greenhouse gas pollution. This study aims to analyze experiences of reuse of organic waste developed in Brazil and reported in scientific articles published in the period from 2010 to 202, with special emphasis on the reuse of decomposition products (i.e. slurry) in the fertilization of urban trees. This is a qualitative research for which the Scientific Electronic Library Online (SCIELO) and Google Scholar platforms were consulted, seeking national articles, through the descriptors: Initiatives reuse of organic waste, urban organic waste, Organic waste composting experience, Composting of organic waste and Reuse of Organic Waste. Thirty-six articles were found, from which, after content analysis, 6 studies were selected whose content met the research interests. It was concluded that the actions that have been developing for the reuse of Organic Waste start from small initiatives, regionalized, with positive results and developed by a portion of the population that chose to act in a sustainable way in the face of the dismay of public entities in the face of sanitary and environmental problems related to the management of Organic waste.

\footnotetext{
1 Professora Universitária, avaliadora do MEC e mestranda em Geoambiental na Universidade Guarulhos

2 Professor do programa de Mestrado da Universidade Guarulhos, Avaliador do MEC, Pesquisador da UNIP, Pesquisador do Centro de Ecologia Funcional da Universidade de Coimbra, Portugal. Editor-Chefe das Revistas Científicas RECIMA21, RECISATEC e ACERTTE.

3 Professor do programa de Mestrado da Universidade Guarulhos.

${ }^{4}$ Professor e coordenador do programa de Mestrado da Universidade Guarulhos.

5 Professor do programa de Mestrado da Universidade Guarulhos.
} 


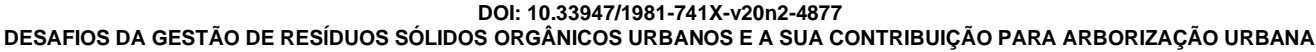 Joelma Telesi Pacheco Conceição, Marcio Magera Conceição, Ricardo Costa, Fabricio Bau Dalmas, Mauricio Lamano Ferreira}

KEYWORDS: Organic Waste. Reuse of organic waste. Waste Management

\section{1- INTRODUÇÃO}

A União Europeia, através de ações determinadas pelo Pacto Ecológico Europeu (2020), vem estabelecendo metas para a redução do descarte de resíduos, mantendo como um dos objetivos centrais, o lixo zero. Tal iniciativa, entre um conjunto de propostas, envolve iniciativas que abandonam o modelo linear de consumo e implementa um ciclo sustentável, onde os produtos são concebidos a partir de matéria prima menos poluente, possivelmente reciclada, apresentando características mais duráveis e modelos produtivos mais econômicos (PARLAMENTO EUROPEU, 2021).

Este conceito inclui todos os resíduos descartados, sejam eles orgânicos ou inorgânicos e responsabilizam cada indivíduo pelo consumo consciente através da aquisição de produtos respeitando e ampliando seu ciclo de vida, bem como o uso e descarte adequados, além da valorização de inciativas de compartilhamento de equipamentos e serviços em função da economia de recursos e redução do descarte, com metas obrigatórias a serem ampliadas e implementadas até 2030.

Reforçando o desenvolvimento de estratégias neste sentido, no início do ano de 2021, o Parlamento Europeu votou um conjunto de ações objetivando uma economia autossustentável, neutra quanto à geração de carbono, incluindo medidas rigorosas e metas obrigatórias para a utilização e consumo de materiais de forma totalmente circular até a data limite de 2050 (PARLAMENTO EUROPEU, 2021).

Durante a 27ํㅡㄹ Conferência das Nações Unidas sobre Mudanças Climáticas (COP26), em Glasgow, na Escócia, lideranças mundiais, ativistas e empresários concordaram com medidas urgentes para o desenvolvimento de um plano de ações que visam o corte na emissão de gases poluentes até 2030. Neste sentido, o governo brasileiro, através do Ministério do Meio Ambiente, assumiu compromisso de redução nas emissões de carbono, conservação das florestas e uso racional de recursos naturais, com geração de emprego verde e crescimento econômico (UOL, 2021).

Embora sejam firmados compromissos internacionais, os desafios internos na área ambiental pertinentes ao Brasil são inúmeros, no que se refere à questão sanitária, a gestão de resíduos sólidos urbanos ainda principia retoricamente pela extinção de seus lixões, pois das 2.315 unidades de disposição dos Resíduos Sólidos Urbanos (RSU) contabilizadas pelo Instituto de Pesquisa Econômica Aplicada (IPEA), 1.114 são classificadas como lixões. Desta forma, 48,1\% dos locais para disposição final estão irregulares, contribuindo gravemente para a poluição. Cabe ressaltar que 580 unidades são aterros controlados $(25,1 \%)$ e apenas 621 atuam como aterros sanitários $(26,8 \%)$ propriamente dito. Este cenário é bastante desafiador para o governo brasileiro, uma vez que diversos compromissos foram assumidos na COP26 e agora serão necessários esforços conjuntos com entidades privadas e sociedade civil (IPEA, p. 195,2019). 


\section{DESAFIOS DA GESTÃO DE RESÍDUOS SÓLIDOS ORGÂNICOS URBANOS E A SUA CONTRIBUIÇÃO PARA ARBORIZAÇÃO URBANA} Joelma Telesi Pacheco Conceição, Marcio Magera Conceição, Ricardo Costa, Fabricio Bau Dalmas, Mauricio Lamano Ferreira

A extinção dos lixões é pauta urgente, visto que estes locais contaminam recursos hídricos e o ar, representando ameaça para a saúde pública, manutenção da biodiversidade e processos naturais em geral, proliferando doenças a partir da contaminação por seus compostos tóxicos liberados, entre outros fatores. Cabe ressaltar que a queima periódica dos resíduos sólidos libera grande quantidade de gases de efeito estufa para atmosfera, intensificando ainda mais a crise climática (ABRELPE, 2017, P.15).

Acerca deste problema, a ONU mantém um programa, através da Comissão das Nações Unidas para Desenvolvimento Regional (UNCRD), cujo objetivo é o fechamento dos lixões no mundo, presentes principalmente nos países em desenvolvimento (ABRELPE, 2017).

Considerando que os lixões contêm resíduos de diversas fontes, tipos, composições este artigo se limitará a analisar a gestão de Resíduos Orgânicos (RO), com especial ênfase para a aplicação de subprodutos como o chorume na arborização urbana, buscando a efetividade da economia circular e o fechamento de ciclos de sustentabilidade. Este trabalho ganha importância ao se considerar que a decomposição do resíduo orgânico compõe $4 \%$ da poluição por gases de efeito estufa no Brasil, valor que corresponde a 96 milhões de toneladas de $\mathrm{CO}_{2}$ equivalentes emitidas.

O uso de produtos da decomposição da matéria orgânica destinada a aterros sanitários tem protagonizado as tentativas de minimizar impactos ambientais em cidades e aumentar a eficiência energética e produtividade de plantas, a depender do uso que se dá para tais dejetos. Na cidade de Niterói, RJ, foi reportado o uso de chorume gerado em uma unidade de alimentação para geração de energia, por meio do biogás. Azevedo et al., (2020) mostraram que a unidade gerou aproximadamente 210 toneladas de resíduos, o que equivale a 266.492,16 kWh por ano. Este valor de energia gerada é suficiente para atender a demanda de 137 residências de médio porte. Além disso, o chorume gerado a partir da decomposição de resíduos orgânicos são subprodutos ricos em compostos de nitrogênio, fósforo e micronutrientes, todos essenciais para o desenvolvimento vegetal. Assim, entende-se que o chorume pode desempenhar papel fundamental para a sustentabilidade ambiental, uma vez que eles podem ser utilizados em viveiros de árvores ou programas de arborização urbana. Tais contribuições podem ter papel fundamental na economia circular, uma vez que aspectos ambientais, econômicos e sociais podem estar envolvidos nesta questão.

Neste sentido, a Lei 12305/2010, denominada Política Nacional de Resíduos Sólidos (PNRS), determina que os Resíduos Orgânicos sejam utilizados como adubo, através da compostagem de pelo menos parte do volume coletado, gerando benefícios pela redução de poluentes e redução do volume encaminhado aos aterros ou lixões (ABRELPE, 2017).

Atualmente, cada brasileiro gera em torno de 1,04 K de Resíduos Sólidos Urbanos por dia, sendo $51,4 \%$, composto por ROs (ABRELPE, 2020). Provenientes de origem animal e vegetal, os ROs são restos de produções, cuja composição é eminentemente orgânica, como restos de alimentos, palha, bagaço, esterco de animais, sobras de poda de árvores, entre outros (BELTRAME, 2020; MMA, 2014).

Embora os ROs componham grande parte do volume dos resíduos descartados e seu potencial como poluidor seja preocupante, iniciativas para reaproveitamento ainda são algo novo e desafiador. 
DESAFIOS DA GESTÃO DE RESÍDUOS SÓLIDOS ORGÂNICOS URBANOS E A SUA CONTRIBUIÇÃO PARA ARBORIZAÇÃO URBANA Joelma Telesi Pacheco Conceição, Marcio Magera Conceição, Ricardo Costa, Fabricio Bau Dalmas, Mauricio Lamano Ferreira

Portanto, baseado nestes desafios supracitados, este estudo tem por objetivo realizar um levantamento sobre experiências aplicadas no reaproveitamento de materiais orgânicos, com especial ênfase no reaproveitamento de dejetos decompostos, como por exemplo na arborização urbana. Este levantamento busca contribuir para que boas práticas sejam replicadas ao mesmo tempo que percalços sejam evitados, auxiliando para que novas iniciativas nesse sentido se desenvolvam. A princípio foram encontrados 36 artigos, sendo 6 deles selecionados após análise do conteúdo por atenderem aos interesses da pesquisa.

\section{2- REFERENCIAL TEÓRICO}

No Brasil, compete aos municípios a responsabilidade pela coleta, transporte e destinação dos Resíduos, bem como a conversão dos lixões em aterros, conforme disposto na Lei Federal № 12.305 que trata da Política Nacional de Resíduos Sólidos (PNRS). A princípio, a data limite estabelecida pela PNRS para a extinção dos lixões foi 2014 , mas pela dificuldade no cumprimento do prazo houve alteração para 31 de dezembro de 2020. Como fato nenhuma das metas foram atingidas. A criação da nova Lei 14.026/2020, em seu artigo 54, além de prorrogar o prazo estabelecido pela PNRS, garantiu exceção para municípios inseridos em plano intermunicipal de resíduos sólidos ou plano municipal de gestão integrada de resíduos sólidos, os quais podem obedecer prazos diferenciados "definidos entre 02 de agosto de 2021 e 02 de agosto de 2024, sendo aplicáveis de acordo com critérios como tamanho e localização do município, inclusão deste em região metropolitana, entre outros" (FROTA e HOSKEN, 2021).

Cabe destacar que a gestão de resíduos fundamenta mais da metade dos Objetivos do Desenvolvimento Sustentável (ODS, 2030) de forma direta ou indireta, presentes em ações de despoluição necessárias e urgentes para a consolidação de cidades verdes sustentáveis, segurança alimentar, saúde e preservação dos recursos naturais (ABRELPE, 2017).

A gestão de RO (origem animal e vegetal) se posicionam no cerne do desafio imposto pelas alterações climáticas por liberarem metano e gás carbônico na atmosfera como resultados de seu processo de decomposição (MORATO E JUNIOR, 2020). Também são preocupantes a poluição do solo e dos recursos hídricos pela produção de chorume, líquido resultante da dissolução de material orgânico, impregnado por bactérias e metais pesados que contaminam o solo e corpos de água superficiais e subsuperficiais (ABRELPE,2017; IPEA, 2019). A classificação dos Resíduos sólidos está diretamente relacionada com o processo ou atividade origem de seus constituintes e características, e a comparação destes constituintes com listagens de resíduos e substâncias cujo impacto à saúde e ao meio ambiente é conhecido". (ABNT, 2004).

Neste contexto, os ROs são definidos como não perigosos (classe II) - fazendo parte deste grupo: restos de comida, cascas de alimentos, galhos, folhas secas, grama etc. (MMA, 2014; ABNT, 2004; BELTRAME, 2021). O fato de não serem considerados perigosos e por serem biodegradáveis manteve em segundo plano a preocupação quanto ao volume de ROs encaminhado para descarte, enquanto os resíduos inorgânicos (latinhas, vidros, papel papelão) foram priorizados, principalmente 
DOI: 10.33947/1981-741X-v20n2-4877
DESAFIOS DA GESTÃO DE RESíDUOS SÓLIDOS ORGÂNICOS URBANOS E A SUA CONTRIBUIÇÃO PARA ARBORIZAÇÃO URBANA
Joelma Telesi Pacheco Conceição, Marcio Magera Conceição, Ricardo Costa, Fabricio Bau Dalmas, Mauricio Lamano Ferreira

após década de 80, em algumas iniciativas que partiram da coleta seletiva e logística reversa com a participação de cooperativas e associações de catadores de materiais reutilizáveis (MAGERA, 2012). No entanto, a falta de conhecimento técnico e planejamento adequado trouxeram prejuízos que conduziram ao fechamento de muitas unidades. Até hoje, apenas $10 \%$ do material inorgânico descartado é reaproveitado e reinserido na cadeia produtiva através da reciclagem (Revista RECIMA21, 2021).

Portanto, o reaproveitamento de ROs ainda se trata de algo desafiador. Na zona rural a fração orgânica dos resíduos é utilizada no seu local de origem, disposta no solo para se degradar naturalmente, atuando como adubo ou como alimento para os animais. Também são desenvolvidas iniciativas para redução do desperdício, através do aproveitamento integral de alimentos vegetais, o que contribui para o aumento da qualidade nutritiva dos alimentos e redução dos resíduos orgânicos gerados (SARINHO, CAVALCANTI E OLIVEIRA, 2021).

Já na área urbana são inúmeros os entraves determinados pelas especificidades demandadas no processo de compostagem dos ROs, embora a legislação responsabilize a administração pública pela destinação adequada e reaproveitamento, conforme determina a Lei 12.305:

Art. 3o Para os efeitos desta lei, entende-se por: VII - destinação final ambientalmente adequada: destinação de resíduos que inclui a reutilização, a reciclagem, a compostagem, a recuperação e o aproveitamento energético ou outras destinações admitidas pelos órgãos do SISNAMA;

Segundo estimativas, até 2012 a quantidade de resíduos sólidos urbanos encaminhados para compostagem não ultrapassava 1\% do volume gerado no país (ABRELPE, 2020; IPEA, 2012).

De acordo com a Associação Brasileira das Empresas de Limpeza Pública e Resíduos Especiais (Abrelpe), compostagem é a denominação para o processo de transformação de resíduos sólidos orgânicos em um adubo bom, barato e de qualidade. Essa decomposição ocorre pela ação de microrganismos, resultando em um composto com potencial fertilizante, melhorando as propriedades físicas, químicas e bioquímicas do solo, podendo adubar as plantas. O adubo obtido a partir da compostagem apresenta boa utilidade como fertilizante orgânico classe $\mathrm{C}$, conforme Instrução Normativa n-25 do Ministério da Agricultura, Pecuária e Abastecimento (MAPA, 2009). Cabe destacar que para a realização da compostagem, é necessária uma triagem dos resíduos, mantendo-se somente as sobras vegetais e restos de animais (ABRELPE, 2020).

Outra técnica de valorização dos RO é através da Biodigestão anaeróbia, que dá origem ao Biogás. Trata-se de uma mistura resultante da fermentação anaeróbia de material orgânico encontrado em resíduos animais e vegetais, lodo de esgoto, lixo ou efluentes industriais, como vinhaça, restos de matadouros, curtumes e fábricas de alimentos. Esta técnica é utilizada na zona rural e oferece boas condições para a transformação de resíduos agroindustriais e mitigação de poluentes (IPEA, 2014).

Entre as dificuldades para o reaproveitamento de orgânicos destaca-se a pouca experiência sobre o tema, portanto, para contribuir com essa questão, este estudo apresenta uma revisão integrativa 
DESAFIOS DA GESTÃO DE RESÍDUOS SÓLIDOS ORGÂNICOS URBANOS E A SUA CONTRIBUIÇÃO PARA ARBORIZAÇÃO URBANA Joelma Telesi Pacheco Conceição, Marcio Magera Conceição, Ricardo Costa, Fabricio Bau Dalmas, Mauricio Lamano Ferreira

sobre artigos selecionados no período de outubro e novembro de 2021 e descritas nos próximos capítulos.

\section{3- MATERIAIS E MÉTODO}

Trata-se de uma pesquisa qualitativa, que segundo Vergara (2007) aplica-se ao conhecimento da natureza de um fenômeno social, por se estruturar na coleta de dados sobre a realidade pesquisada e sua análise posterior de forma indutiva. Com a finalidade de sintetizar estudos desenvolvidos sobre 0 reaproveitamento de resíduos orgânicos, utilizou-se de uma revisão integrativa de literatura. Para isso, a pesquisa se deu em seis etapas que incluíram: a seleção da questão e tema para o estudo; critérios para a seleção dos artigos; leitura e análise do material selecionado; categorização das pesquisas; análise das informações obtidas e apresentação dos resultados (SILVA, 2005).

A princípio foram consultadas as plataformas Scientific Electronic Library Online (SCIELO) e Google Acadêmico, buscando artigos desenvolvidos no intervalo de tempo de 2010 até 2021, através dos descritores: Iniciativas reaproveitamento de resíduos orgânicos, Resíduos orgânicos urbanos, Resíduos orgânicos experiência de compostagem e Compostagem de resíduos orgânicos e Reaproveitamento de Resíduos Orgânicos.

Este levantamento limitou-se a conhecer quais experiências vem ocorrendo em território nacional e quais os resultados destas iniciativas de reaproveitamento de orgânicos, bem como entraves encontrados durante o desenvolvimento dos projetos, sejam eles custeados pelo poder público, ONGs ou entidades privadas. A princípio foram encontrados 36 artigos, que após análise foram selecionados e reduzidos para 6 artigos, cujo conteúdo atendia aos interesses da pesquisa.

Foram excluídos artigos duplicados, teses, resumos e estudos que não abordam com clareza as experiências realizadas. As informações obtidas a partir da leitura e análise de cada um dos 6 artigos selecionados, foram dispostos em planilha Excel, versão 2016, para demonstrar os resultados de forma objetiva.

\section{4- RESULTADOS E DISCUSSÃO}

Cabe salientar que o material pesquisado, composto por artigos publicados no período de onze anos, contou com a utilização de diferentes métodos aplicados de acordo com o atendimento dos objetivos e critérios pretendidos por cada pesquisador. O conjunto de informações obtidas serviram de base para a análise a seguir, fornecendo uma síntese sobre experiências desenvolvidas por diversas iniciativas no reaproveitamento dos ROs.

O Quadro 1 apresenta uma síntese das principais informações obtidas de cada artigo selecionado para a presente pesquisa. 
DOI: $10.33947 / 1981-741 X-v 20 n 2-4877$

DESAFIOS DA GESTÃO DE RESÍDUOS SÓLIDOS ORGÂNICOS URBANOS E A SUA CONTRIBUIÇÃO PARA ARBORIZAÇÃO URBANA Joelma Telesi Pacheco Conceição, Marcio Magera Conceição, Ricardo Costa, Fabricio Bau Dalmas, Mauricio Lamano Ferreira

Quadro 1 - Sistematização dos artigos referentes a iniciativas de reaproveitamento de Resíduos orgânicos no período de 2010 a 2021.

\begin{tabular}{|c|c|c|c|}
\hline $\begin{array}{c}\text { Título/ } \\
\text { autores/ano }\end{array}$ & Objetivo & Método & Resultados \\
\hline $\begin{array}{l}\text { 1-Reaproveitamento } \\
\text { de resíduos } \\
\text { orgânicos regionais } \\
\text { agroindustriais da } \\
\text { Amazônia Tocantina } \\
\text { como substratos } \\
\text { alternativos na } \\
\text { produção de mudas } \\
\text { de alface. } \\
\text { Parreira, Mariana C; } \\
\text { Correa, Breno } \\
\text { Almeida, Martins, } \\
\text { Jefferson dos Santos, } \\
\text { Ribeiro Rafael Coelho, } \\
\text { Silva, Evaldo Morais } \\
\text { da.,( 2019). }\end{array}$ & $\begin{array}{l}\text { O objetivo do } \\
\text { trabalho foi avaliar } \\
\text { a influência de } \\
\text { resíduos orgânicos } \\
\text { da agroindústria da } \\
\text { Amazônia } \\
\text { Tocantina no } \\
\text { desenvolvimento } \\
\text { inicial de cultivares } \\
\text { de alface. }\end{array}$ & $\begin{array}{l}\text { O delineamento experimental } \\
\text { utilizado foi o de blocos ao } \\
\text { acaso, em esquema fatorial } 4 \\
\text { x } 5 \text {, com cinco repetições. Os } \\
\text { tratamentos consistiram na } \\
\text { combinação de quatro } \\
\text { substratos (palmito de açaí, } \\
\text { caroço de açaí, casca de } \\
\text { arroz carbonizada e o } \\
\text { substrato comercial) e cinco } \\
\text { cultivares de alface } \\
\text { (Veneranda, Simpson, } \\
\text { Cinderela, Mônica e Gabriela). }\end{array}$ & $\begin{array}{l}\text { O substrato com resíduos da } \\
\text { agroindústria de palmito se mostrou } \\
\text { uma ótima alternativa para produção } \\
\text { de mudas de alface proporcionando } \\
\text { resultados semelhantes ao substrato } \\
\text { comercial, além de possuir } \\
\text { características de favoráveis de ser } \\
\text { mais barato e ajudar na } \\
\text { sustentabilidade do meio ambiente. }\end{array}$ \\
\hline $\begin{array}{l}\text { 2-Reaproveitamento } \\
\text { de resíduos sólidos } \\
\text { na cadeia } \\
\text { agroindustrial do } \\
\text { pescado } \\
\text { Lima, Leandro } \\
\text { Kanamaru Franco de } \\
\text { (2013). }\end{array}$ & $\begin{array}{l}\text { O aumento da } \\
\text { produção e do } \\
\text { consumo de } \\
\text { pescado está } \\
\text { diretamente ligado } \\
\text { à necessidade de } \\
\text { se viabilizar } \\
\text { tecnologias para } \\
\text { o reaproveitamento } \\
\text { dos resíduos } \\
\text { gerados pela } \\
\text { indústria aquícola. } \\
\text { Nessa revisão, são } \\
\text { apresentadas três } \\
\text { importantes } \\
\text { tecnologias de } \\
\text { reaproveitamento } \\
\text { dos resíduos } \\
\text { sólidos gerados em } \\
\text { entrepostos } \\
\text { de pescado } \\
\text { (farinha de } \\
\text { pescado, óleo de } \\
\text { pescado e } \\
\text { compostagem } \\
\text { de pescado), com } \\
\text { o objetivo de } \\
\text { conhecer as } \\
\text { particularidades, os } \\
\text { fundamentos, e os } \\
\text { principais } \\
\text { problemas } \\
\text { associados ao } \\
\text { manejo e à } \\
\text { qualidade do } \\
\text { produto final. }\end{array}$ & $\begin{array}{l}\text { Nessa revisão, são } \\
\text { apresentadas três importantes } \\
\text { tecnologias de } \\
\text { reaproveitamento dos } \\
\text { resíduos sólidos gerados em } \\
\text { entrepostos de pescado } \\
\text { (farinha de pescado, óleo de } \\
\text { pescado e compostagem de } \\
\text { pescado), com o objetivo de } \\
\text { conhecer as particularidades, } \\
\text { os fundamentos, e os } \\
\text { principais problemas } \\
\text { associados ao manejo e à } \\
\text { qualidade do produto final. }\end{array}$ & $\begin{array}{l}\text { Apesar da simples tecnologia } \\
\text { empregada, existem, no Brasil, poucas } \\
\text { informações sobre a taxa de } \\
\text { decomposição dos resíduos } \\
\text { provenientes da piscicultura ou de } \\
\text { entrepostos de peixes em } \\
\text { composteiras. Geralmente, os resíduos } \\
\text { da segunda classe são os que } \\
\text { apresentam maior potencial para } \\
\text { implantação de tecnologias de } \\
\text { reaproveitamento nas agroindústrias. } \\
\text { Por conseguinte, podem apresentar } \\
\text { alta capacidade de valorização desde } \\
\text { que inseridos em processos } \\
\text { adequados de reutilização consciente. } \\
\text { Diversas formas de reaproveitamento } \\
\text { têm surgido com o objetivo de gerar } \\
\text { novos produtos com diferentes } \\
\text { aplicações a partir dos resíduos } \\
\text { agroindustriais. Além disso, os gastos } \\
\text { despendidos no desenvolvimento e na } \\
\text { aplicação de novas tecnologias para } \\
\text { essa atividade pode significar um } \\
\text { retorno financeiro para a própria } \\
\text { indústria geradora. }\end{array}$ \\
\hline
\end{tabular}


DOI: $10.33947 / 1981-741 X-v 20 n 2-4877$

DESAFIOS DA GESTÃO DE RESÍDUOS SÓLIDOS ORGÂNICOS URBANOS E A SUA CONTRIBUIÇÃO PARA ARBORIZAÇÃO URBANA Joelma Telesi Pacheco Conceição, Marcio Magera Conceição, Ricardo Costa, Fabricio Bau Dalmas, Mauricio Lamano Ferreira

\begin{tabular}{|c|c|c|c|}
\hline $\begin{array}{l}\text { Barbosa, Ana Paula } \\
\text { Ferreira; Souza, } \\
\text { Rakelyne Costa de; } \\
\text { Dias, João Felipe } \\
\text { Maia; Almeida, Jose } \\
\text { Felipe Tavares de; } \\
\text { Borges, Fernando } \\
\text { José; Freitas, } \\
\text { Idelfonso Colares de, } \\
\text { (2019). }\end{array}$ & $\begin{array}{l}\text { O objetivo foi } \\
\text { promover a } \\
\text { conscientização da } \\
\text { comunidade } \\
\text { educacional sobre } \\
\text { questões } \\
\text { ambientais, com } \\
\text { foco na } \\
\text { problemática de } \\
\text { resíduos sólidos } \\
\text { orgânicos e } \\
\text { apresentar a } \\
\text { compostagem } \\
\text { como um excelente } \\
\text { recurso para a } \\
\text { diminuição destes } \\
\text { resíduos. O projeto } \\
\text { constituiu } \\
\text { inicialmente com a } \\
\text { implantação da } \\
\text { compostagem, que } \\
\text { foi realizada com } \\
\text { os resíduos sólidos } \\
\text { orgânicos, } \\
\text { provenientes da } \\
\text { merenda escolar. }\end{array}$ & $\begin{array}{l}\text { O método se tratou de um } \\
\text { estudo de caso a partir da } \\
\text { experimentação com a } \\
\text { implantação da compostagem, } \\
\text { que foi realizada com os } \\
\text { resíduos sólidos orgânicos, } \\
\text { provenientes da merenda } \\
\text { escolar, coletados num } \\
\text { período de } 23 \text { dias, } \\
\text { descartando os sábados e } \\
\text { domingos. Ao invés de } \\
\text { descartados, os resíduos } \\
\text { foram transformados em um } \\
\text { composto, rico em matéria } \\
\text { orgânica, que foi destinado a } \\
\text { horta implantada nas } \\
\text { dependências da escola. }\end{array}$ & $\begin{array}{l}\text { Por fim, pôde-se compreender que a } \\
\text { compostagem surgiu como uma } \\
\text { alternativa viável para o } \\
\text { reaproveitamento do lixo orgânico da } \\
\text { comunidade escolar. Verificou-se a } \\
\text { partir desta experiência a possibilidade } \\
\text { de ser desenvolvida em qualquer } \\
\text { unidade de ensino, desde que haja } \\
\text { incentivos por partes dos educadores e } \\
\text { da direção das escolas. }\end{array}$ \\
\hline $\begin{array}{l}\text { 4-Gerenciamento de } \\
\text { resíduos orgânicos } \\
\text { provenientes de } \\
\text { restaurante industrial } \\
\text { de Mina Cauê, } \\
\text { complexo minerador } \\
\text { de Itabira/MG. }\end{array}$ & $\begin{array}{l}\text { Objetivou avaliar a } \\
\text { geração dos } \\
\text { resíduos orgânicos } \\
\text { provenientes de } \\
\text { um restaurante } \\
\text { industrial, } \\
\text { localizado no } \\
\text { Complexo } \\
\text { Minerador de } \\
\text { Itabira/MG, } \\
\text { identificando os } \\
\text { custos associados } \\
\text { à sua destinação } \\
\text { final e mostrando } \\
\text { as iniciativas } \\
\text { implantadas para o } \\
\text { reaproveitamento } \\
\text { do resíduo gerado. }\end{array}$ & $\begin{array}{l}\text { Foram analisadas as planilhas } \\
\text { disponibilizadas pela empresa } \\
\text { responsável pelo restaurante } \\
\text { da Mina Cauê, tais como o } \\
\text { controle da sobra limpa e o } \\
\text { resto ingesta, custo mensal } \\
\text { relacionado à destinação final } \\
\text { e o controle de resíduos } \\
\text { processados. Foram avaliados } \\
\text { e deduzidos os dados } \\
\text { numéricos levantados na } \\
\text { amostra. O método tornou } \\
\text { possível uma comparação da } \\
\text { quantidade de resíduo } \\
\text { orgânico gerado durante o } \\
\text { ano de } 2014 \text { e entre os meses } \\
\text { de janeiro a setembro de } \\
2015 \text {, além da quantidade de } \\
\text { resíduo processado e } \\
\text { disponibilizado para o } \\
\text { reaproveitamento; a redução } \\
\text { dos resíduos gerados e custos } \\
\text { após a implantação das ações } \\
\text { de melhoria. }\end{array}$ & $\begin{array}{l}\text { Com relação a disposição final dos } \\
\text { resíduos orgânicos no aterro sanitário, } \\
\text { observou-se que durante o período } \\
\text { analisado houve uma redução de } \\
64,67 \% \text { dos valores inicialmente pagos. } \\
\text { No aspecto relacionado ao desperdício } \\
\text { verificou-se que as campanhas } \\
\text { desenvolvidas objetivando o } \\
\text { "desperdício zero" tanto dos } \\
\text { funcionários do restaurante como dos } \\
\text { clientes, também influenciaram } \\
\text { positivamente na redução de resíduos } \\
\text { "resto ingesta". }\end{array}$ \\
\hline
\end{tabular}




\begin{tabular}{|c|c|c|c|}
\hline $\begin{array}{l}\text { 5-Resíduos Orgânicos } \\
\text { Urbanos: Um olhar } \\
\text { sobre Florianópolis }\end{array}$ & $\begin{array}{l}\text { O artigo analisou } \\
\text { diversas experiências } \\
\text { aplicadas na cidade } \\
\text { de Florianópolis - SC } \\
\text { que resultaram na } \\
\text { destinação correta de } \\
\text { aproximadamente } 400 \\
\text { toneladas de } \\
\text { Resíduos Orgânicos, } \\
\text { valorizados através da } \\
\text { compostagem, o que } \\
\text { equivale a 5\% dos } \\
\text { Resíduos Orgânicos } \\
\text { gerados pelo } \\
\text { município. Apresenta } \\
\text { um panorama destas } \\
\text { iniciativas, buscando } \\
\text { descrever o papel dos } \\
\text { órgãos públicos, da } \\
\text { comunidade e das } \\
\text { empresas privadas } \\
\text { envolvidas, bem como } \\
\text { as tecnologias de } \\
\text { tratamento de } \\
\text { resíduos orgânicos } \\
\text { usadas e os volumes } \\
\text { processados. }\end{array}$ & $\begin{array}{l}\text { Foi realizada uma pesquisa } \\
\text { bibliográfica e documental, além } \\
\text { de levantamento de dados por } \\
\text { meio de entrevistas, visitas } \\
\text { técnicas a empresas e } \\
\text { participação em workshops. O } \\
\text { estudo abordou iniciativas voltadas } \\
\text { à valorização de resíduos } \\
\text { orgânicos no município de } \\
\text { Florianópolis, capital de Santa } \\
\text { Catarina, descrevendo o sistema } \\
\text { de coleta convencional de } \\
\text { resíduos urbanos em Florianópolis } \\
\text { e as várias ações voltadas ao } \\
\text { tratamento e valorização dos } \\
\text { resíduos orgânicos desenvolvidas } \\
\text { pela COMCAP, responsável pela } \\
\text { coleta urbana, e pelas várias } \\
\text { organizações não governamentais, } \\
\text { comunidade e empresas privadas } \\
\text { em Florianópolis. }\end{array}$ & $\begin{array}{l}\text { O principal obstáculo para o tratamento de } \\
\text { resíduos orgânicos urbanos está na divisão } \\
\text { dos custos do sistema, o que onera o } \\
\text { município e acomoda a população, inibindo } \\
\text { uma mudança } \\
\text { de cultura mais profunda da população em } \\
\text { geral. Se os } \\
\text { cidadãos fizerem sua parte e trabalharem em } \\
\text { conjunto com o município, as companhias } \\
\text { gestoras } \\
\text { de resíduos teriam mais autonomia para } \\
\text { alocar seus recursos de maneira mais } \\
\text { adequada. } \\
\text { Foi identificado que a falta de financiamento } \\
\text { e de políticas de incentivos e apoio a este } \\
\text { tipo de iniciativa, ou seja, ao tratamento de } \\
\text { resíduos orgânicos urbanos, limita o } \\
\text { crescimento dos volumes processados e } \\
\text { dificulta a profissionalização neste setor. }\end{array}$ \\
\hline $\begin{array}{l}\text { 6-Gerenciamento de } \\
\text { resíduos sólidos } \\
\text { orgânicos da UFGD por } \\
\text { meio da compostagem }\end{array}$ & $\begin{array}{l}\text { Viabilizar o uso da } \\
\text { compostagem no } \\
\text { tratamento e } \\
\text { gerenciamento dos } \\
\text { resíduos sólidos } \\
\text { orgânicos gerados no } \\
\text { campus da } \\
\text { Universidade Federal } \\
\text { da Grande Dourados } \\
\text { (UFGD), na cidade de } \\
\text { Dourados, Mato } \\
\text { Grosso do Sul. O } \\
\text { experimento foi } \\
\text { realizado na } \\
\text { Incubadora de } \\
\text { Tecnologias Sociais e } \\
\text { Solidárias da UFGD } \\
\text { (ITESS/UFGD). }\end{array}$ & $\begin{array}{l}\text { A leira de compostagem foi } \\
\text { elaborada seguindo o método já } \\
\text { utilizado na Universidade Federal } \\
\text { de Santa Catarina (UFSC), } \\
\text { denominado compostagem } \\
\text { termofílica em leira estática com } \\
\text { aeração natural. A montagem da } \\
\text { leira foi realizada utilizando-se } \\
\text { pequenas ferramentas como pás, } \\
\text { enxadas, uma balança, e resíduos } \\
\text { orgânicos como restos de } \\
\text { alimentos do restaurante } \\
\text { universitário (RU), resíduos dos } \\
\text { biotérios, como cama de rato e de } \\
\text { coelho, aparas de grama do } \\
\text { campus, inoculante biológico e } \\
\text { galhos secos. Antes da reposição } \\
\text { diária de material orgânico, a } \\
\text { temperatura da leira era } \\
\text { monitorada, a fim de certificar-se a } \\
\text { ocorrência do seu aumento } \\
\text { gradual. }\end{array}$ & $\begin{array}{l}\text { A leira experimental elaborada na UFGD } \\
\text { comprovou a eficiência do processo de } \\
\text { compostagem termofílica em leiras estáticas } \\
\text { com aeração natural para o tratamento dos } \\
\text { resíduos sólidos orgânicos gerados no } \\
\text { campus, demonstrando-se uma ótima } \\
\text { alternativa para a destinação e tratamento } \\
\text { correto desses materiais, além de ser um } \\
\text { processo fácil de ser utilizado e de baixo } \\
\text { custo. }\end{array}$ \\
\hline
\end{tabular}

Fonte: autores

Todas as iniciativas analisadas se desenvolveram de forma local, em projetos que incluíram a sociedade civil em arranjos a partir dos ROs captados nas proximidades, algo que se mostrou viável por dispensar gastos com transporte e evitar a contaminação dos ROs com outro tipo de material, com composição e toxidade diferentes, conforme Luna e Zambon (2018). Além disso, o material obtido a partir da compostagem vem sendo aproveitado em hortas e jardins locais, fato que incentiva a produção 
DESAFIOS DA GESTÃO DE RESÍDUOS SÓLIDOS ORGÂNICOS URBANOS E A SUA CONTRIBUIÇÃO PARA ARBORIZAÇÃO URBANA Joelma Telesi Pacheco Conceição, Marcio Magera Conceição, Ricardo Costa, Fabricio Bau Dalmas, Mauricio Lamano Ferreira

da comunidade e encerra de maneira sustentável a gestão dos resíduos captados (LIMA, 2013; LUNA, ZAMBOM 2018; BARBOSA et al., 2019; CORREA et al., 2019).

Outro dado observado se refere à tecnologia adotada, sendo que a compostagem esteve presente e se mostrou eficiente, de acordo com as técnicas aplicadas, nos artigos Parreira et al. (2019); Barbosa et al. (2019); Luna, Zambon (2018) e Vilela, Piesanti (2015) e quando bem manejada possibilita alternativas que contribuem para a mitigação de poluentes. No entanto, foram destacados o alto custo pela coleta, a dificuldade para a segregação dos resíduos na fonte geradora e a falta de incentivos econômicos (LUNA, ZAMBON, 2018). As experiências também trazem o potencial de serem ambientalmente educativas quando aplicadas a partir de tecnologia simples, podendo ser replicadas, multiplicando resultados, conforme relato de Barbosa et al. (2019).

Alguns artigos trouxeram experiências que trataram do reaproveitamento dos ROs antes mesmo do seu descarte, planejando ações onde são gerados, conforme relatado nos estudos de Fonseca Barcelos et al. (2017) e Lima (2013). O controle do volume de resíduos gerados, através de um estudo aprofundado sobre os hábitos de consumo e descarte de alimentos a partir da realidade de um restaurante industrial, mostrou que é possível utilizar e oferecer cardápios e campanha educativa que reduzam o desperdício, trazendo ganhos para o negócio, para os clientes e para o meio ambiente (FONSECA BARCELOS et al., 2017).

Acerca do mesmo conceito, a reutilização do material descartado durante o processo produtivo trouxe bons resultados no reaproveitamento dos ROs gerados em entrepostos de pescado, transformando materiais em adubo pela própria indústria geradora, conforme estudo desenvolvido por Lima (2013).

A análise dos estudos demonstrou que as 6 experiências analisadas obtiveram resultados positivos, enfatizando a educação ambiental como fundamental para a implementação e bons resultados dos projetos. A triagem dos orgânicos trata-se de um diferencial importante para evitar a contaminação e melhor qualidade do material obtido, algo evidenciado nos projetos que envolveram a compostagem.

Cabe destacar que embora a gestão dos ROs seja extremamente necessária, o manejo de produtos e subprodutos da decomposição da matéria orgânica merece atenção especial por parte dos tomadores de decisão. A próxima parte deste artigo apresentará alguns casos de sucesso no reaproveitamento do chorume na arborização urbana. Esta alternativa pode ter implicações ambientais, sociais e econômicas quando bem administradas, sendo uma ação com forte aptidão para a promoção da economia circular.

\section{Uso de produtos da decomposição de resíduos sólidos orgânicos urbanos na produtividade vegetal}

A produção de chorume a partir de resíduos sólidos orgânicos urbanos decompostos pode ter inúmeras finalidades, dentre as quais podem-se destacar o uso dos nutrientes em produção de mudas e fertilização vegetal. O uso da matéria orgânica para fins de agricultura e silvicultura está se tornando 


\section{DOI: $10.33947 / 1981-741 X-v 20 n 2-4877$ \\ DESAFIOS DA GESTÃO DE RESÍDUOS SÓLIDOS ORGÂNICOS URBANOS E A SUA CONTRIBUIÇÃO PARA ARBORIZAÇÃO URBANA} Joelma Telesi Pacheco Conceição, Marcio Magera Conceição, Ricardo Costa, Fabricio Bau Dalmas, Mauricio Lamano Ferreira

mais popular, o que pode ter função ambiental, social e econômica quando bem planejada. Ostos et al., (2008) desenvolveram um trabalho sobre produtividade de plântulas de Pistacia lentiscus L. sob diferentes tipos de nutrição. Os autores substituíram turfa por chorume oriundo dos resíduos sólidos urbanos que impactam negativamente as cidades, além de lodo de esgoto e casca de pinheiro e mostraram que a substituição de turfa em viveiros tem se mostrado uma alternativa ecológica e produtiva no cultivo e propagação do arbusto Pistacia lentiscus L., uma vez que esta espécie é bastante utilizada em programas de reflorestamento na região do Mediterrâneo. Outro exemplo seria o trabalho de Oyedele et al., (2008), os quais observaram os efeitos do chorume gerado a partir dos resíduos sólidos urbanos nas propriedades físico-químicas do solo, com o cuidado para potenciais contaminantes, ie. metais pesados. Os autores encontraram autos valores para os contaminantes estudados, com especial ênfase para o chumbo $(\mathrm{Pb})$, os quais se correlacionaram positivamente com a absorção feita pelas plantas. Além disso, o fator de transferência expresso como a razão da concentração de metais pesados nas plantas em relação ao solo variou significativamente entre as amostras coletadas no meio do aterro e em uma área controle, destacando um provável risco de intoxicação para os vegetais. No entanto, aspectos nutricionais contrapõem os benefícios para a produtividade das plantas como um todo.

No Brasil, especificamente na cidade de Seropédica, RJ, Abreu et al., (2017) utilizaram produtos da decomposição de resíduos sólidos urbanos na produção de mudas de Lafoensi pacari. Os autores reportaram que as plantas cujo solo foi nutrido com o chorume gerado apresentaram melhor desenvolvimento biométrico e produtivo do que as plantas tratadas com adubo comercial, destacando a eficiência da adubação a partir do produto decomposto.

Uma condição urbana, porém, não doméstica, refere-se ao uso de produtos da poda de árvores de ruas e avenidas. Este resíduo orgânico pode ser reutilizado na produtividade vegetal. Mendonça et al., (2021) estudaram a viabilidade de uso de resíduos da poda de árvores, destacando propriedade físicas, químicas e estruturais e encontraram $\mathrm{pH}$, condutividade elétrica e teores de metal pesado adequados, porém, a razão $\mathrm{C}: \mathrm{N}$ mostrou-se inadequada. Os autores concluíram que mais estudos precisam ser feitos neste sentido, de modo que se feche o ciclo da sustentabilidade ambiental com o manejo da arborização urbana. No Estado de São Paulo, Oliveira e Viani (2020) utilizaram chorume para o cultivo de Euterpe edulis, uma palmeira muito abundante na Mata Atlântica e com grande importância para a manutenção da fauna. Os autores identificaram que o tratamento a partir dos subprodutos de origem de resíduos sólidos foram eficientes no desenvolvimento das plantas in loco. Estes resultados ressaltam a importância de utilizar mecanismos alternativos na adubação de plantas, sejam em condições controladas de viveiros ou em campo propriamente ditas.

A Organização das Nações Unidas declarou no ano de 2021 a década da restauração de ecossistemas, a qual preconiza um reflorestamento em massa de áreas abandonadas ou com potencial para abrigar a biodiversidade. Estratégias que visam a maior produção de mudas, a maior produtividade florestal, apresentam baixo custo e que sejam sustentáveis, devem ser priorizadas em detrimentos às metodologias antigas. Desta forma, sugere-se que atores responsáveis pelo tratamento de resíduos 
DESAFIOS DA GESTÃO DE RESÍDUOS SÓLIDOS ORGÂNICOS URBANOS E A SUA CONTRIBUIÇÃO PARA ARBORIZAÇÃO URBANA

Joelma Telesi Pacheco Conceição, Marcio Magera Conceição, Ricardo Costa, Fabricio Bau Dalmas, Mauricio Lamano Ferreira

sólidos urbanos e steakholders da gestão ambiental busquem parcerias produtivas com o setor de reflorestamento, de modo que o ciclo de sustentabilidade ambiental possa ser (parcialmente) fechado.

\section{5- CONSIDERAÇÕES FINAIS}

Este trabalho mostra algumas dimensões do desafio da gestão de resíduos sólidos orgânicos urbanos, especialmente nas perspectivas de parcerias público-privadas, disponibilidade de uma equipe técnica, infraestrutura adequada e educação ambiental da população para a separação dos resíduos gerados. Alguns trabalhos chamam atenção especial para o reaproveitamento de ROs, o qual vem sendo desenvolvidos localmente, de maneira regionalizada, muitas vezes por iniciativa da própria população em parceria com entidades privadas e organizações do terceiro setor, haja visto que exigem um montante menor de investimento.

Para municípios brasileiros ainda é complexa a implementação de unidades para a compostagem de seus resíduos orgânicos, algo percebido pelas raras iniciativas relatadas quando realizadas buscas através de estudos sobre o tema. O encerramento dos lixões e as campanhas para a separação correta dos resíduos de acordo com suas características, na fonte geradora através de campanhas educativas para a população, são passos fundamentais que contribuiriam para a gestão adequada dos ROs, no entanto ainda estão distantes da prática.

Percebe-se que as ações que vem se desenvolvendo partem de pequenas iniciativas, regionalizadas, desenvolvidas por uma parcela da população que optou por agir diante do descaso das entidades públicas frente aos problemas sanitários e ambientais relacionados à gestão de ROs. Mas ainda é necessário muito mais quando se trata de questões ambientais. Divulgar os casos de sucesso para que possam sem replicados e aprimorados pode contribuir para encorajar novas iniciativas neste sentido. Mas, sem a participação direta do poder público local, o destino correto e o aproveitamento dos resíduos orgânicos vão continuar insipiente e sem resultados ambientais e econômicos, o que poderia viabilizar sua implantação como cultura de gestão pública.

As possíveis alternativas de uso de produtos e subprodutos da decomposição dos resíduos que vão para aterros e lixões podem contribuir para a minimização do problema ambiental e melhoria do quadro sustentável de uma determinada região. A arborização urbana pode ser favorecida caso tomadores de decisão desejem fazer uma gestão dos ROs mais efetiva. A literatura científica mostra inúmeros benefícios vegetais com a aplicação de chorume na adubação.

Cabe, portanto assim, apenas o registro de experiências locais desenvolvidas sobre o tema e que lograram algum sucesso, mas sem um volume de escala que justificasse tal investimento. 


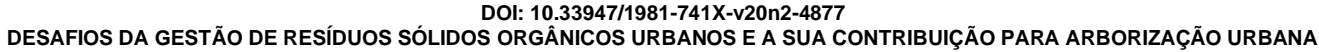 Joelma Telesi Pacheco Conceição, Marcio Magera Conceição, Ricardo Costa, Fabricio Bau Dalmas, Mauricio Lamano Ferreira \\ REFERÊNCIAS}

ASSOCIAÇÃO BRASILEIRA DE EMPRESAS DE LIMPEZA PÚBLICA E RESÍDUOS ESPECIAIS (ABRELPE) (2013) Caderno Informativo de Recuperação Energética. Comitê de Valorização Energética. São Paulo: ABRELPE. Disponível em: Arte final Plastivida 2.indd (crq4.org.br) Acesso em: 15 jan. 2021.

(2021) Panorama dos resíduos sólidos no Brasil 2020. São Paulo: ABRELPE. Disponível em: https://abrelpe.org.br/panorama-2020/.Acesso em: 28 ago. 2021. Paulo: ABRELPE.

(2017) Roteiro para Encerramento de Lixões Os lugares mais poluídos do mundo. São

ASSOCIAÇÃO BRASILEIRA DE NORMAS TÉCNICAS. NBR 10004: Resíduos Sólidos

Classificação. Rio de Janeiro, p. 5. 2004. Disponível em: <https://supremoambiental.com.br/wpcontent/uploads/2018/07/nbr-n-10-004-abnt-2004-residossolidos.pdf\#: :text=NBR\%20n.\%2010004\%20\%28ABNT\%2C\%202004\%29\%20\%20Res\%C3\%ADdos\%20S\%C3\%B3lidos,estes\%20res\%C3\%ADduos\%20possam\%20ter\%20manusei 0\%20e\%20destina\%C3\%A7\%C3\%A30\%20adequados >. Acesso em: 21 abr. 2021.

Azevedo, A. R. et al. (2020). Characterization of solid waste of restaurant and its energy generation potential: case study of Niterói, RJ, Brazil. Biomass Conversion and Biorefinery, p.1-10.

BARBOSA, Ana Paula Ferreira, et al. Reaproveitamento de resíduos sólidos orgânicos oriundo da merenda escolar por meio da compostagem. Braz. Ap. Sci. Rev.,Curitiba, v.3, n. 2, p. 1161-1168, mar./abr. 2019.

BELTRAME, Kátia Goldschimidt. Compostagem e os desafios da destinação dos Resíduos Orgânicos no Brasil. 18/11/2020. Comitê de Integração dos resíduos Sólidos. Disponível em: $<$ https://smastr16.blob.core.windows.net/home/2020/11/abisolo-sima-cirs.pdf $>$. Acesso em: 10 out. 2021.

BRASIL. (2014). Ministério do Meio Ambiente. Plano de Gerenciamento de Resíduos Sólidos. Instrumento de Responsabilidade Socioambiental na Administração Pública. Secretaria de Articulação Institucional e Cidadania Ambiental. Brasília, 2014.

FONSECA, Barcelos Francy Nara, et al. Gerenciamento de resíduos orgânicos provenientes do restaurante industrial da Mina Cauê, Complexo Minerador de Itabira/MG. Research, Society and Development, v. 6, n. 1, 2017.

FROTA, Leandro Melo; HOSKEN, Rodrigo Santos. Cartilha sobre o Novo Marco Legal do Saneamento Básico: Lei $n^{\circ}$ 14.026/2020. coordenador: Leandro Mello Frota, Rodrigo Santos Hosken 2. ed. rev. e atual. Brasília: OAB Editora, 2021.

IPEA (2012) INSTITUTO ECONÔMICO DE PESQUISA APLICADA Brasil coleta $\mathbf{1 8 3 , 5}$ mil toneladas de resíduos sólidos/ dia. Disponível em:

$<$ https://www.ipea.gov.br/portal/index.php?option=com content\&id=13932>. 2012. Acesso em: 12 out. 2021.

IPEA (2019) INSTITUTO ECONÔMICO DE PESQUISA APLICADA. Diagnóstico dos Resíduos Sólidos Urbanos. Relatório de Pesquisa. Disponível em:

http://www.ipea.gov.br/agencia/images/stories/PDFs/relatoriopesquisa/121009 relatorio residuos solid os urbanos.pdf. Acesso em: 08 nov. 2021. 


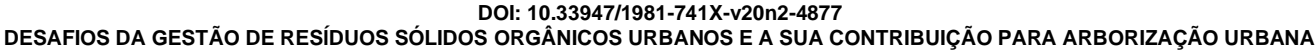 Joelma Telesi Pacheco Conceição, Marcio Magera Conceição, Ricardo Costa, Fabricio Bau Dalmas, Mauricio Lamano Ferreira}

LIMA, Leandro Kanamaru Franco de. Reaproveitamento de resíduos sólidos na cadeia agroindustrial do pescado. Embrapa Pesca e Aquicultura. Palmas TO, 2013.

LUNA, Monica Maria Mendes; ZAMBON, Matheus. Resíduos Orgânicos Urbanos: um olhar sobre Florianópolis. Encontro Internacional sobre Gestão Empresarial e Meio ambiente. 2018. Disponível em: $<$ (PDF) RESÍDUOS ORGÂNICOS URBANOS: UM OLHAR SOBRE FLORIANÓPOLIS (researchgate.net)>. Acesso em: 10 out. 2021.

MAGERA, Márcio Conceição. Os Caminhos do Lixo: da obsolescência programada à logística reversa. Campinas/SP: Editora Átomo, 2012.

Viabilidade econômica da reciclagem dos resíduos domésticos da cidade de Coimbra Utilizando o aplicativo VERDES. Revista Multidisciplinar RECIMA21 [online]. 2021, v. 2, n. 2, p. 427 440. Disponível em:https://doi.org/10.47820/recima21.v2i2.103. ISSN: 2675-6218. Acesso em: 10 out. 2021.

MENDONÇA, V. M. M., et al. (2021). Characterization of organic compost from urban pruning waste. Research, Society and Development, v. 10, n. 6, e38110615830-e38110615830.

MOURATO, Ana Eveline Mendonça Lima; JúNIOR, Osvaldo Jorge Pinto. Quantificação de Gases de Efeito Estufa em Aterro Sanitário no Município de Cuiabá. GESTA, v. 8, n. 2, 2020.

ORGANIZAÇÃO DAS NAÇÕES UNIDAS, Programa das Nações Unidas para o Meio Ambiente: Perspectiva de la Gestión de Residuos en América Latina y el Caribe, 2018. Disponível em: https://wedocs.unep.org/bitstream/handle/20.500.11822/26448/ Residuos LAC ES.pdf?sequence $=1$ \&isAllowed $=y$.

OSTOS, J. C., et al. (2008). Substitution of peat for municipal solid waste-and sewage sludge-based composts in nursery growing media: Effects on growth and nutrition of the native shrub Pistacia lentiscus L. Bioresource technology, v. 99, n. 6, p. 1793-1800.

OYEDELE, D. J.; GASU, M. B. J.; AWOTOYE, O. O. (2008). Changes in soil properties and plant uptake of heavy metals on selected municipal solid waste dump sites in Ile-Ife, Nigeria. African Journal of Environmental Science and Technology, v. 2, n. 5, p. 107-115.

PARLAMENTO EUROPEU, Eficiência em termos de recursos e economia circular. Disponível em: https://www.europarl.europa.eu/factsheets/pt/sheet/76/ eficiencia-em-termos-de-recursos-e-economiacircular. 2021. Acesso em: 10 maio 2021.

PARREIRA, Mariana C., et al. Reaproveitamento de resíduos orgânicos regionais agroindustriais da amazônia tocantina como substratos alternativos na produção de mudas de alface. Revista Brasileira de Agropecuária Sustentável. June 2019 Disponível em:

<https://www.researchgate.net/publication/333998377>. Acesso em: 02 nov. 2021.

SARINHO, Ana Maria Maciel; CAVALCANTI, Mayra da Silva; OLIVEIRA, Igor Macêdo de. Aproveitamento integral dos alimentos: sustentabilidade e utilização de farinhas modificadas. RECIMA21 - Revista Científica Multidisciplinar. v. 2, n. 10, 2021.

SILVA, E. L. da; MENEZES, E.M. Metodologia da pesquisa e elaboração de dissertação. 4. ed. rev. atual. Florianópolis: UFSC, 2005. 138 p. 
DOI: 10.33947/1981-741X-v20n2-4877 DESAFIOS DA GESTÃO DE RESídUOS SÓLIDOS ORGÂNICOS URBANOS E A SUA CONTRIBUIÇÃO PARA ARBORIZAÇÃO URBANA
Joelma Telesi Pacheco Conceição, Marcio Magera Conceição, Ricardo Costa, Fabricio Bau Dalmas, Mauricio Lamano Ferreira

Uol. COP26: Brasil promete reduzir emissões pela metade até 2030. Disponível em: $<$ https://noticias.uol.com.br/ultimas-noticias/bbc/2021/11/01/cop26-brasil-promete-reduzir-emissoespela-metade-ate-2030-e-zerar-desmatamento-2-anos-antes.htm?cmpid=copiaecola $>$. Acesso em: 21 out. 2021.

VILELA, Danielle Marques; PIESANTI, Jéssica Lopes. Gerenciamento de resíduos sólidos orgânicos da ufgd por meio da compostagem. Revista Ciência e Extensão, v. 11, n. 3, p. 28-39, 2015. 